\title{
Natural Jute Fibre-Reinforced Polymer Composite System for Posttensioned Beam Strengthening in Flexure
}

\author{
D. P. Archana $\left(\mathbb{D},{ }^{1}\right.$ H. N. Jagannatha Reddy $\mathbb{D}^{1},{ }^{1}$ N. Jeevan $\left(\mathbb{D},{ }^{1}\right.$ R. Prabhakara $\left(\mathbb{D},{ }^{2}\right.$ \\ M. U. Aswath $\mathbb{D}^{1}{ }^{1}$ and Basavaraju Paruti $\mathbb{D D}^{3}$ \\ ${ }^{1}$ Department of Civil Engineering, Bangalore Institute of Technology, Bengaluru 560004, India \\ ${ }^{2}$ Structural Engineering, VTU, Belagavi 590018, India \\ ${ }^{3}$ Department of Hydraulics and Water Resource Engineering, HHIOT Campus, Ambo University, Ambo, Ethiopia
}

Correspondence should be addressed to D. P. Archana; archanadpbit@gmail.com and Basavaraju Paruti; basavaraj.paruti@ ambou.edu.et

Received 9 September 2021; Accepted 10 November 2021; Published 27 November 2021

Academic Editor: Ravichandran M

Copyright $(2021$ D. P. Archana et al. This is an open access article distributed under the Creative Commons Attribution License, which permits unrestricted use, distribution, and reproduction in any medium, provided the original work is properly cited.

\begin{abstract}
Existing structures require repair and strengthening owing to degradation caused by incorrect design and construction, environmental impacts, or structural upgradation to meet new seismic design standards or to correct execution problems that occurred during construction. These strengthening requirements can be satisfied by a variety of strengthening techniques. The creation of a fibre-reinforced polymer (FRP) composite system offers a new design method for the strengthening of existing structures. In this study, posttensioned beams are strengthened by using sustainable materials such as natural jute fibre-reinforced polymer (FRP) composites. The performance of these composite systems in the flexural strengthening of posttensioned beams was used to assess their effectiveness. Consequential result for longitudinal reinforcement throughout the length of the beam for flexural strengthening was evaluated. Flexural performance, crack width, ductility, and load-deflection relationship study of control beams (Scheme A) and retrofitted beams (Schemes B and C) under different wrappings were considered in the investigation. An experimental study depicts that using the full wrapping (FW) technique increases the flexural strength of PSC beams wrapped in JFRP by $23 \%$ and, by using the strip wrapping (SW) technique, the flexural strength is increased by $10 \%$. The JFRP composite system of strengthening has shown the highest deformability index and showed that the JFRP material has enormous potential as a structural strengthening material.
\end{abstract}

\section{Introduction}

Structural strengthening and rehabilitation have grown in popularity over the last decade because of their obvious benefits and applications. A lot of research has looked into the flexural and shear behaviour of artificial fibre-reinforced concrete structures in the literature. Badawi and Soudki [1] conducted extensive research on the flexural behaviour of reinforced and plain concrete beams with glass and carbon fibre-reinforced polymer (GFRP and CFRP) confinement, which demonstrated enhanced structure performance by minimizing the cracks. A report by Toutanji et al. [2] demonstrated that the load carrying capacity is drastically improved by the number of layers in the composite system. In detail, Esfahani et al. [3] showed how the reinforcement ratio affects the properties of the beam strengthened by CFRP composites. Syed Ibrahim et al. [4] studied the behaviour of steel fibre-reinforced concrete beams strengthened with GFRP laminates. When compared to reference RC beams, these beams performed well in tests. Al-Deen Bsisu et al. [5] investigated the flexural behaviour of steel- and CFRP-strengthened reinforced concrete beams. Esfahani et al. [3], Ashour et al. [6], Garden and Hollaway [7], and Smith and Teng [8] conducted experimental studies that revealed three major failure categories in concrete structures retrofitted with FRP. Mahalingam et al. [9] experimentally conducted the strength and ductility study of externally bonded steel fibre-reinforced concrete beams. GFRP laminates were used as an externally bonded material. Beams were evaluated for their static responses in terms of strength, 
ductility, and stiffness. The results reveal that externally bonded laminates were more effective than internal fibre reinforcements. Khalifa et al. [10] observed shear deficiencies in artificial carbon fibre composite-retrofitted beams. There is potential for developing new materials with improved properties for the strengthening of structures and their improvement [11]. Diverse materials have been used for structural upgrades in order to meet some criteria for the sake of sustainability and improved quality with functional efficiency [12]. Alam et al. [13] used chemically treated kenaf fibre, jute rope, and jute fibres to prepare composites that were used in the application for strengthening RC structures. Bhutta et al. [14] tested the structural performance of concrete beams strengthened with natural Kenaf FRP. Chin et al. [15] considered pineapple leaf fibre-epoxy composite plates for strengthening reinforced concrete beams. Fibres were alkali-treated to improve their efficiency. Fibre loading was varied between 0.1 and $0.4 \mathrm{v} / \mathrm{v}$ and was used for external $\mathrm{RC}$ beam strengthening. Strengthened beams were tested under four-point bending. The beam strengthened with composite plates has a larger beam capacity (approximately 7\%) than the reference beam, according to the test results. At a fibre volume ratio of $40 \%$, the maximum flexural strength of 301.94 MPa was achieved. Di Luccio et al. [16] demonstrated the feasibility of retrofitting RC walls using flax fibrereinforced polymers, and results were compared with reference wall and carbon fibre-reinforced polymer-strengthened wall. Flax fibre-reinforced polymer-strengthened RC wall specimens showed better strength and ductility gains, and also, the tests show that walls strengthened with flax FRP generally dissipate more energy than those strengthened with CFRP. Sen and Reddy [17] compared the natural to artificial fibre-reinforced polymer composite-retrofitted RC beams for their flexure strength, strengthening significantly improved ductility, flexural strength, and load-deflection behaviour. Alam and Al Riyami [18] investigated the use of natural FRP (sisal, jute, and kenaf) laminates for the strengthening of concrete beams under shear. Sen and Reddy [19] worked on the strengthening of RCC beams with bamboo FRP. Ghalieh et al. [20] investigated the efficacy of hemp fibre-reinforced composites, and Sen and Reddy [21] studied the strengthening of beams with coir FRP for load carrying capacity. Computational techniques have become an important tool to model, analyze, and optimize the parameters/characteristics that affect the properties of natural FRP composites. Mulenga et al. [22] reviewed various computational tools including support vector machines, decision trees, K-means, K-nearest neighbor, Naive Bayes, and artificial neural networks (ANNs). Kumar et al. [23] studied the machining characteristics of natural abaca, hemp, and Mudar fibre particle-reinforced polymer composite using the ANN. Pujari et al. [24] predicted the water absorption capacity of natural fibre-reinforced epoxy composites using artificial neural network and regression analysis. Predicted physical property of natural fibre composites was compared among two methodologies. The ANN shows better results than the regression analysis.

A review of the literature revealed the behaviour and effect of fibre-reinforced polymer composites (both artificial and natural) strengthening on RC beams under flexural loading systems. There has been little research on retrofitting structures, which has been limited to the use of naturally occurring fibres. Very few researchers attempted to evaluate the flexural behaviour of artificial fibre-reinforced composite system-strengthened posttensioned beams. But, it has been clear from the literature that none of the work was reported on the strengthening of posttensioned beams using natural fibre-reinforced polymer composite system. So, in this research study, the purpose is to determine the influence of natural JFRP on the posttensioned concrete beams, structurally retrofitted, and to improve the flexural behaviour of the concrete beams.

1.1. Research Significance. The following issues are intended to be addressed in the current research investigation: (a) the first step is to investigate the feasibility/applicability of using a natural fibre system to strengthen beams and improve their performance and (b) the second objective is to comprehend the flexural capacity of the posttensioned beams wrapped with jute fibre-reinforced polymer (JFRP) composites. The authors investigated JFRP composites for their mechanical properties to confirm their suitability [25].

\section{Materials and Procedure}

OPC 53 grade (Ultratech Cement grade 53) conforming to IS 12269-1987 and locally available river sand were used. A coarse aggregate of $12 \mathrm{~mm}$ was crushed (angularly) in accordance with IS 383:1970. Calculated proportions of water, cement, coarse aggregate, and fine aggregate were mixed in the ratio of 0.4:1:2.13:1.27 to prepare concrete, according to IS 10262-2009 standards and design strength of $40 \mathrm{~N} / \mathrm{mm}^{2}$. The ratio of water and cement allowed was max. 0.55 as per IS: $456-2000$, and workability was found to be $100 \mathrm{~mm}$, measured from the slump cone. Cubes were casted according to the designed mix proportion. Average compression strength was measured at different intervals and was found to be $22.7 \mathrm{~N} / \mathrm{mm}^{2}$ for 7 days, $38.95 \mathrm{~N} / \mathrm{mm}^{2}$ for 14 days, and $43.34 \mathrm{~N} / \mathrm{mm}^{2}$ for 28 days of curing. An epoxy resin (MBrace ${ }^{\circledR}$ Saturant) was used. In addition, as reinforcement, $8 \mathrm{~mm}$ diameter Fe 500 HYSD bars with a tensile strength of $500 \mathrm{~N} / \mathrm{mm}^{2}$ were used.

2.1. Specimensfor Testing. A total of nine beams under three configurations were fabricated as per calculated mix proportions in a single stage. The configurations are (i) control beams (CB) (3 no's), (ii) beams with full wrapping (FW) configuration (3 no's), and (iii) beams with strip wrapping (SW) configuration (3 no's). Table 1 represents all three test beam configurations.

Wood molds having dimensions of $3400 \mathrm{~mm}$ (length) $\times$ $300 \mathrm{~mm}$ (width) $\times 260 \mathrm{~mm}$ (breadth) were used. Lubricant oil was sprayed on the inner walls to facilitate removal after 1 day of curing. The steel reinforcement, along with the sheathing pipe assembly, was placed inside the mold with a $25 \mathrm{~mm}$ clear cover shown in Figure 1. The concrete was then poured into the mold, left for one complete day for solidifying, and cured 
TABLE 1: Beam details.

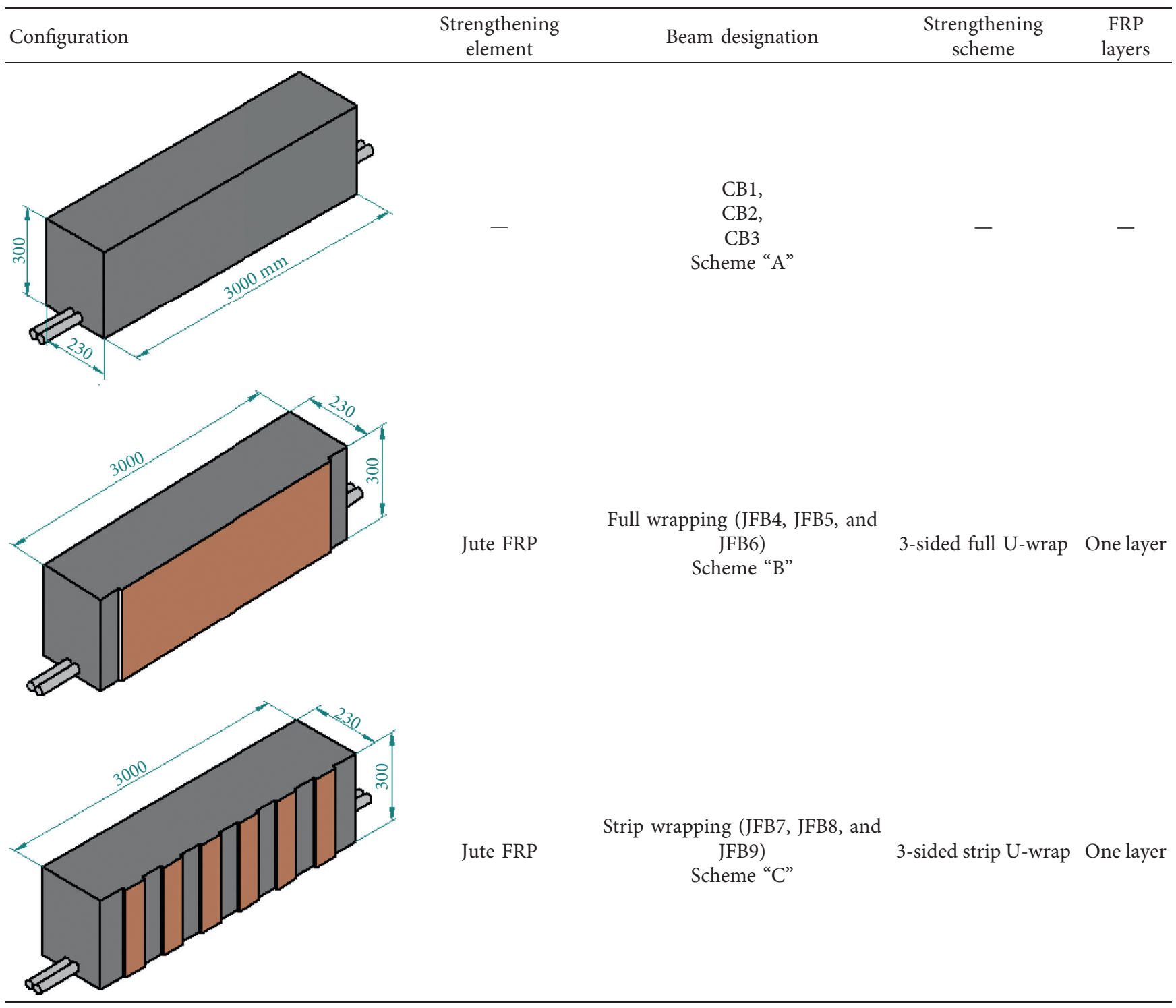

CB: control beam; JFB: jute fibre-retrofitted beam.

for 28 days. Proper compaction was accomplished with $20 \mathrm{~mm}$ needle vibrator. Figures $2(\mathrm{a})-2(\mathrm{~h})$ show the complete procedure followed during the casting of beams.

The beam was stressed with the help of a hydraulic Jack. Three surfaces of the beam (except the top surface) were grounded and cleaned to ensure proper bonding between the laminate and the beam. Then, a thin coat of primer is applied on all three sides in Schemes " $B$ " and " $C$ " beams. The resin and hardener were mixed according to the manufacturer's recommendations, which is $3: 1$. The resin and hardener proportions were calculated, and resin and hardener were thoroughly mixed and applied to the beam surfaces. Hand layup technique was used for retrofitting, whereas U-wrapping configuration of pretreated mats was used to bond the beams to form natural FRP composites. The laminates were then pressed with light pressure to ensure the removal of trapped air. Curing of beams was permitted. For the retrofitting, all of the manufacturer's guidelines were followed.

2.2. Configurations. Scheme "A" beams were designed as control beams without JFRP, with three PSC beam specimens' models labelled CB1, CB2, and CB3. In Scheme B, the beams were designed with $\mathrm{FW}$ technique $90^{\circ}$, U-wrap (three sided), and single-layer laminate bonded to the three sides of the beams, which included three PSC beam models designated as JFB4, JFB5, and JFB6. Scheme "C" beams were designed with the SW technique $90^{\circ}$, U-wrap (three sided), and single-layer laminate is bonded to the beam comprising three RC beam models designated as JFB7, JFB8, and JFB9. Flexural strengthening was evaluated using all beams. The 

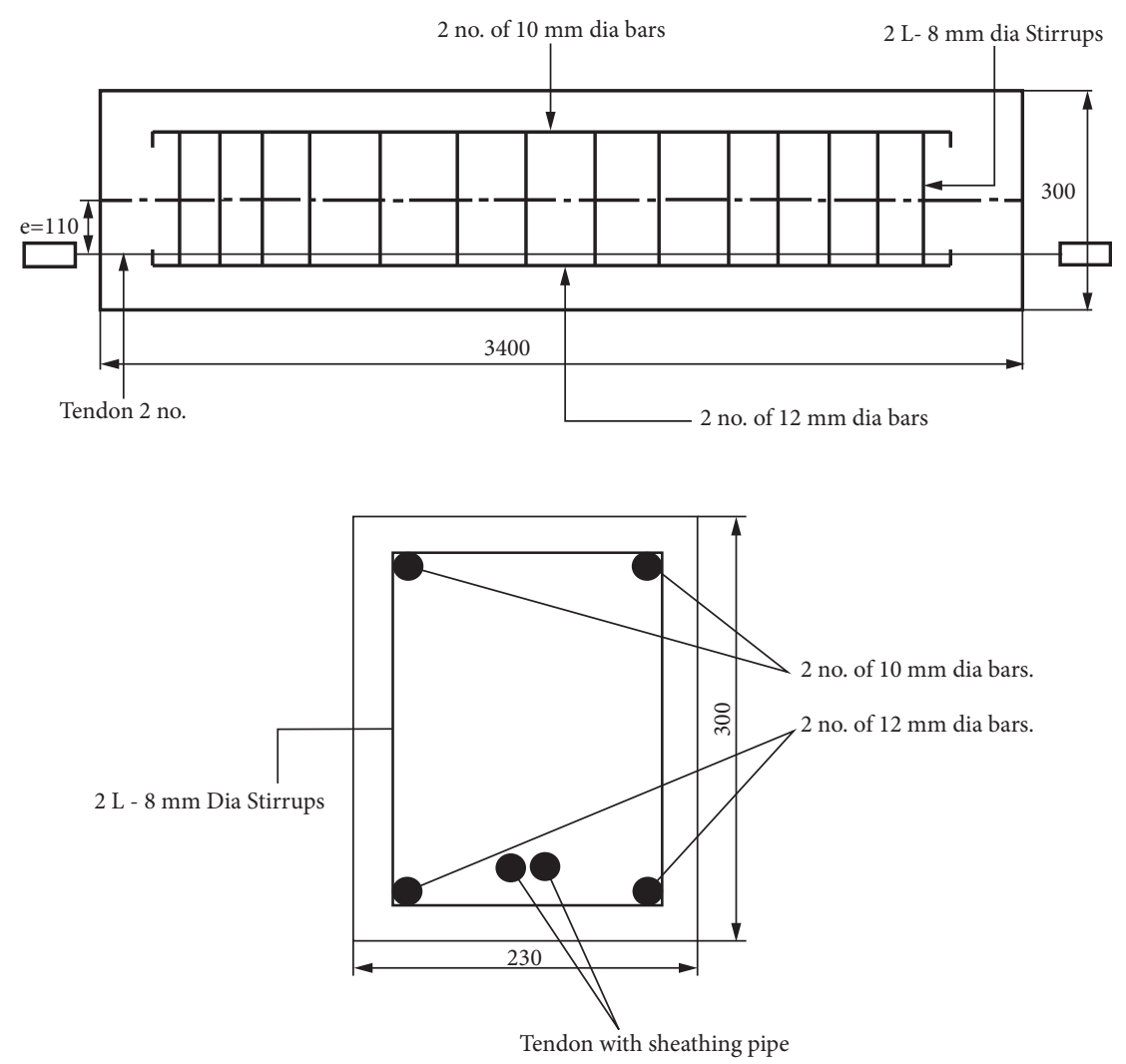

Figure 1: Beam reinforcement structure.

beam configurations and strengths are summarized (Table 2). Uniform reinforcement was used in all beams in order to measure the strengthening effectiveness with and without JFRP wrappings.

\section{Experimental Study}

Figure 3 depicts the results of the experiments. Three experimental schemes (detailed in Table 1) were used to evaluate the strengthening effect under flexure. The beam behaviour under flexure was studied experimentally using a loading frame of 50-tonne capacity. Load applied using a hydraulic jack. To measure the loading increments, a loading cell is attached to the jack and intern to a digital indicator. A four-point bending system was used to test all beams over a $2100 \mathrm{~mm}$ simply supported span with a shear span of $700 \mathrm{~mm}$. The spreader beam was used to apply two-point load, which transfers the load from the loading jack to the specimen. Under the beam, three digital deflection gauges were installed: two beneath the loads and one in centre were used to measure deflection. The manual load was applied in $2 \mathrm{kN}$ span with a hand-held lever until failure. Figure 4 depicts experiments on control, fully wrapped, and stripwrapped beams.

3.1. Failure Mode Study, Load-Deflection Relationship, and Ultimate Strength. Flexural performance assessment study of control beams (Scheme A) and retrofitted beams (Schemes B and C) was conducted, and the beams were designed to undergo flexural failure. They were all tested using a two-point loading arrangement in accordance with the standard procedure. The following were noted and addressed: (i) load-deflection relationship, (ii) ultimate failure load, and (iii) fracture mode study.

3.2. Crack Width Study under Working Loads. During the experiment, strengthened and unstrengthened beams were subjected to different working loads, for which the crack width was measured (Figure 4(c)), and these are compared with the codal requirement. The measured values are found to be within the codal requirement. Experimental observations confirmed that the cracking behaviour of the beams was significantly altered by the use of FRP wraps.

\section{Experimental Results}

The ultimate strength of three sets of beams was tested: Scheme "A," Scheme "B," and Scheme "C." During the experiment, the deflection behaviour and the ultimate load of the beams were observed. The load carrying capacity of the beams in Scheme "A," CB1, CB2, and CB3, was lower than those of Scheme "B" (fully strengthened) and Scheme " $C$ " (partially strengthened) beams. In a single-layer $90^{\circ}$ fully wrapped JFRP, the value of ultimate strength was found to be the highest in Scheme "B": JFB4, JFB5, and JFB6. In order to achieve $50 \%$ of total area strengthening, in Scheme "C," the beams were strengthened by single-layer $90^{\circ}$ strip wrapping with JFRP and have shown ultimate 

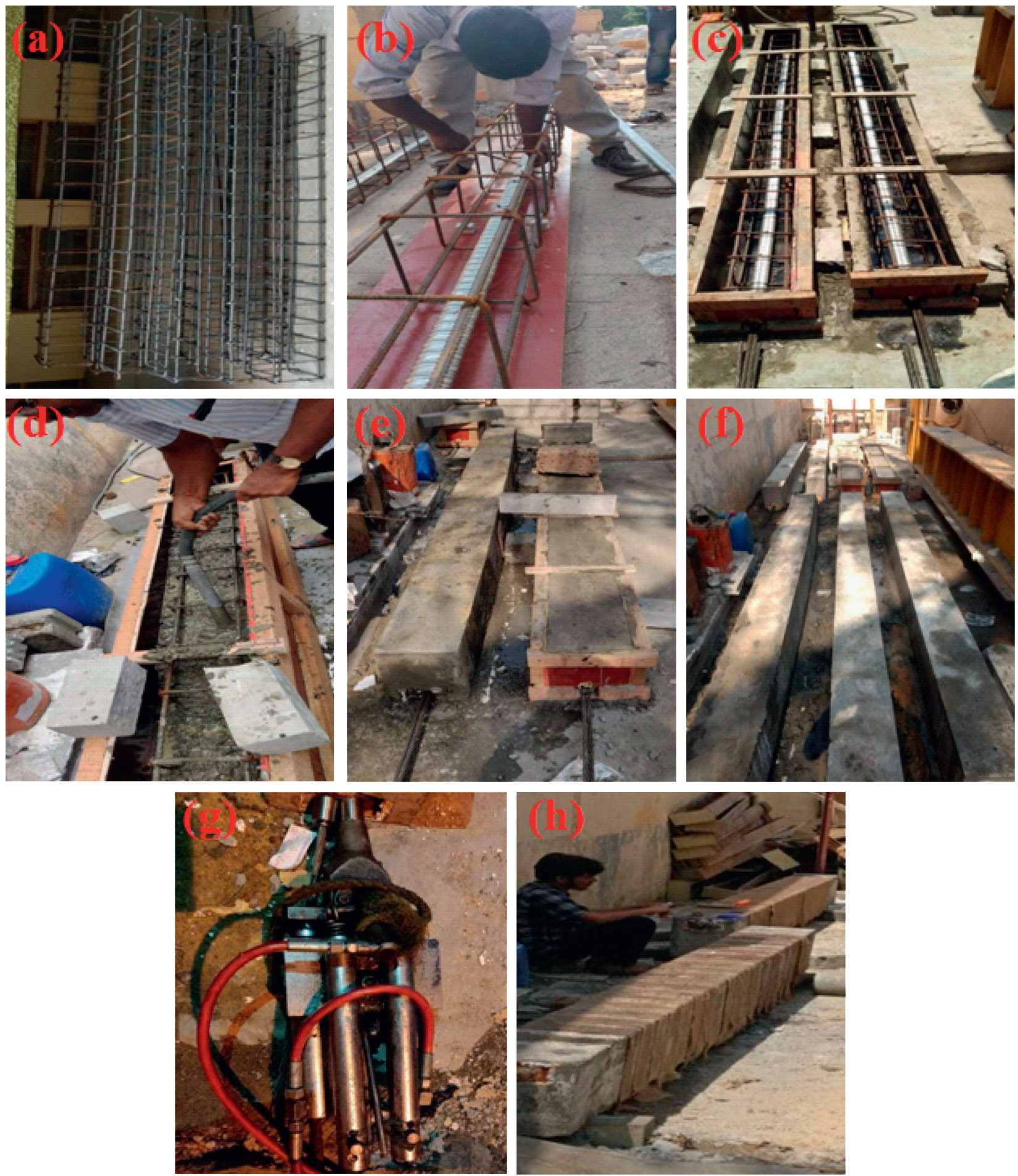

Figure 2: Procedure adopted. (a) Steel reinforcement. (b) Anchorage. (c) Sheathing pipe installation. (d) Pouring concrete and compacting with vibrator. (e) Beams to solidify in the mold for 24 hrs. (f) Beams after burr removal. (g) Stressing with hydraulic jack. (h) Jute mat wrap.

TABle 2: Experimental findings.

\begin{tabular}{cccccc}
\hline Scheme & $\begin{array}{c}\text { Beam } \\
\text { designation }\end{array}$ & $\begin{array}{c}\text { Failure of } \\
\text { FRP }\end{array}$ & $\begin{array}{c}\text { First crack load } \\
\text { (Avg.) kN }\end{array}$ & $\begin{array}{c}\text { Ultimate load } \\
\text { (Avg.) kN }\end{array}$ & $\begin{array}{c}\text { Increase in load carrying capacity over control beam- } \\
\text { strengthening effect (\%) }\end{array}$ \\
\hline "A" & $\begin{array}{c}\text { CB1, CB2, and } \\
\text { CB3 }\end{array}$ & - & 82 & 140 & - \\
"B" & $\begin{array}{c}\text { JFB4, JFB5, and } \\
\text { JFB6 }\end{array}$ & Yes & 130 & 172 & 23 \\
"C" & $\begin{array}{c}\text { JFB7, JFB8, and } \\
\text { JFB9 }\end{array}$ & No & 114 & 154 & 10 \\
\hline
\end{tabular}




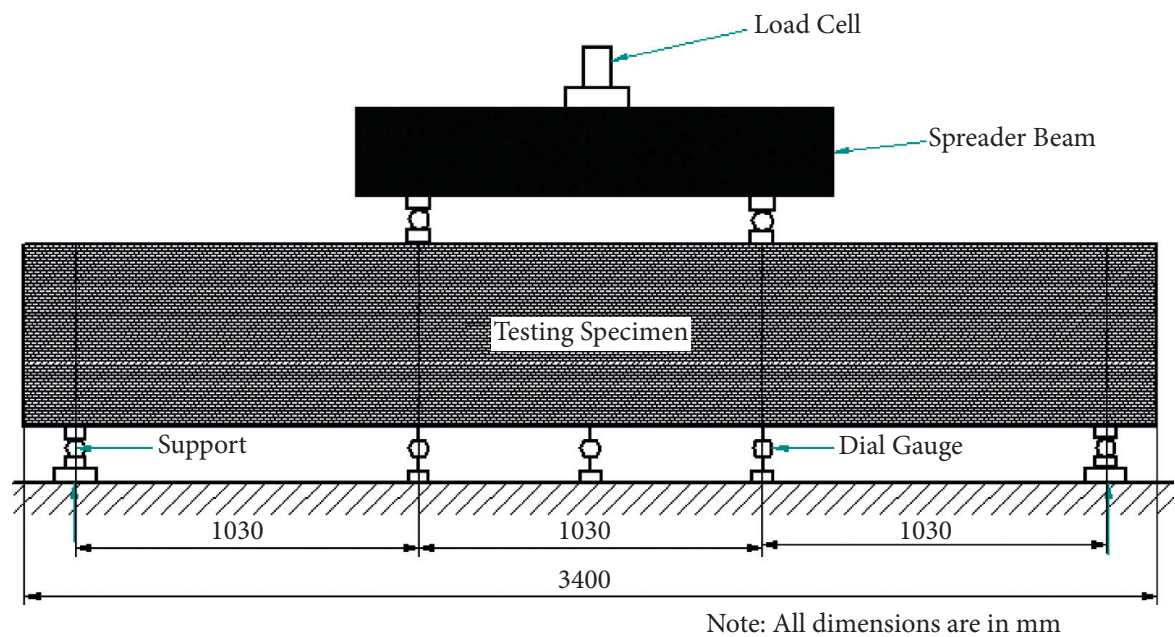

FIGURE 3: Details of experimentation.
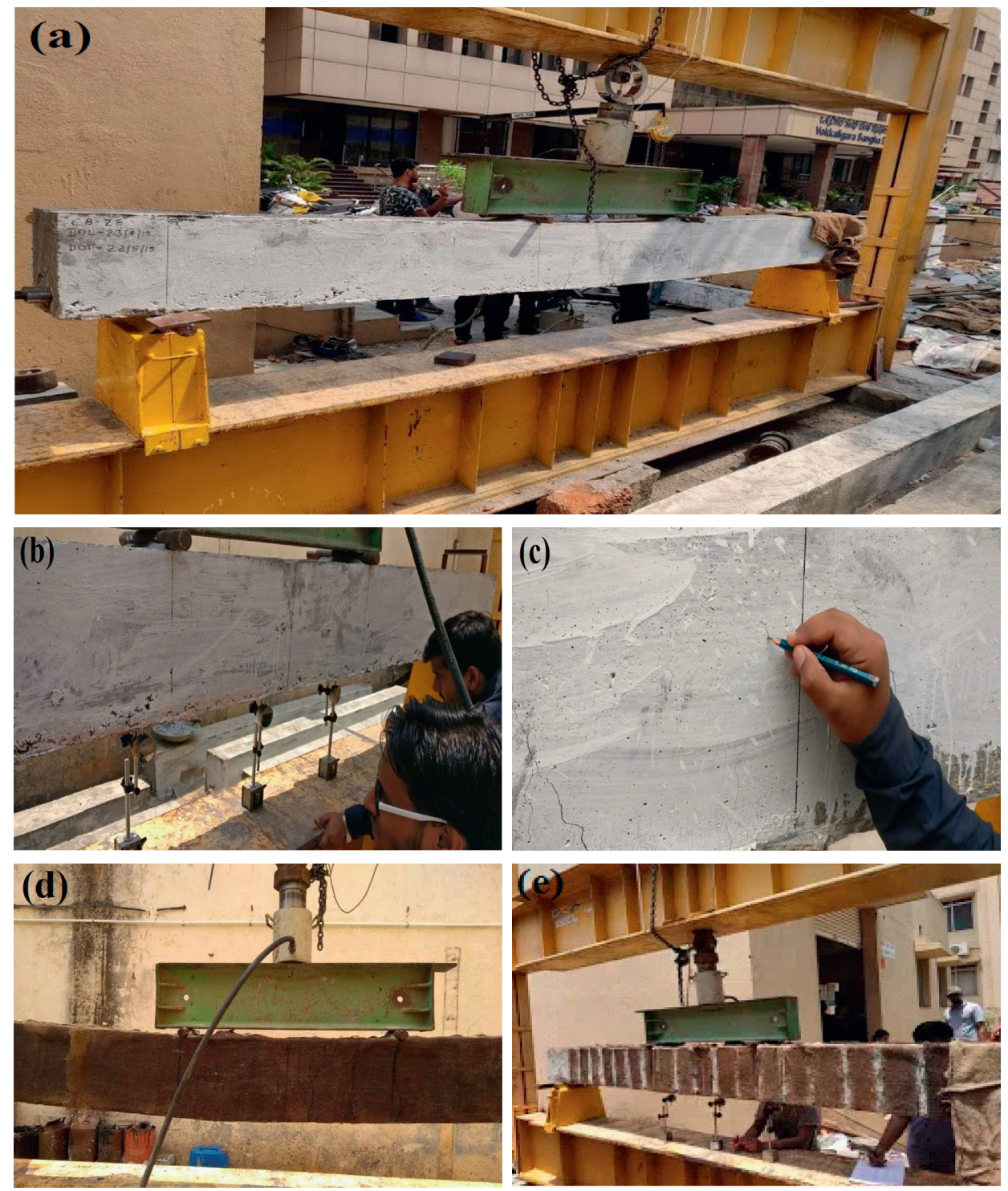

FIgURE 4: (a) Control beam placed on the loading frame. (b) Dial gauge measurements. (c) Crack on CB. (d) Jute fibre FW. (e) Jute fibre SW. 


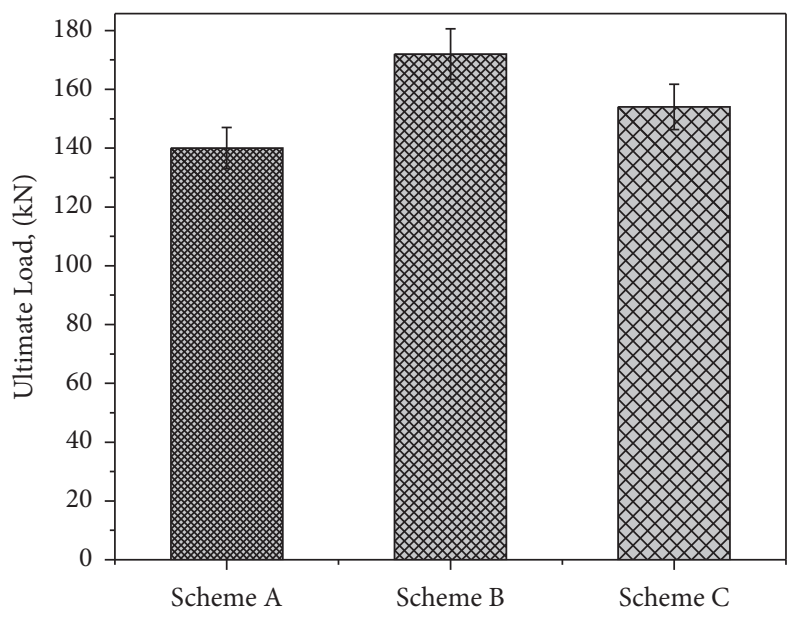

Figure 5: All scheme beams with maximum load carrying capacity.

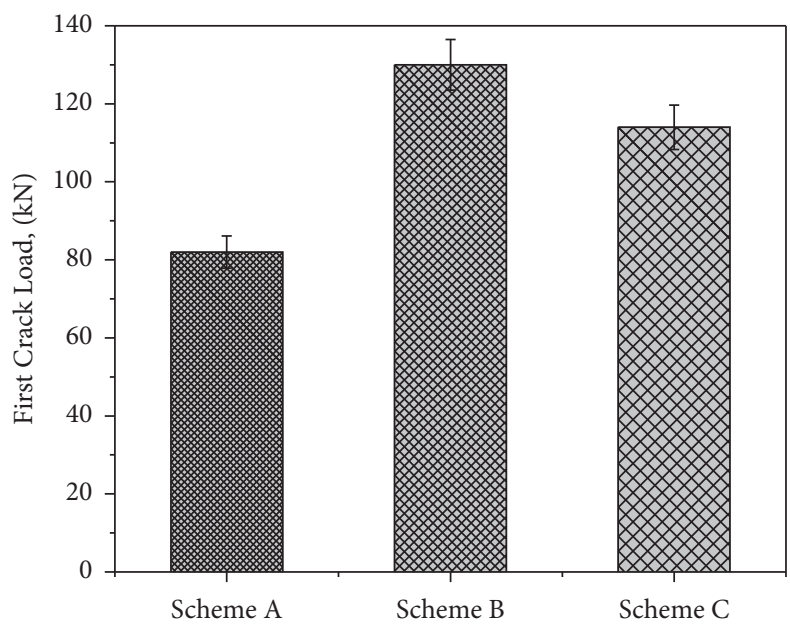

FIGURE 6: First crack load of beams under three schemes.

strength greater than the control beams. These bonded strips have the width of $80 \mathrm{~mm}$ and are at $160 \mathrm{~mm} \mathrm{C} / \mathrm{C}$ (at a clear gap of $80 \mathrm{~mm}$ ). Table 2 summarizes the experimental findings of all beam schemes.

4.1. Failure Mode Study and Ultimate Failure Load. During experimentation, various failure modes were observed. The first set of beams, Scheme "A," failed in flexure, demonstrating that the beams were lacking in flexure. Cracks were observed in the pure flexure zone, which is located in the middle of the span length. These cracks began on the lower face of the beam and progressed to the top face. Scheme "A" beams' ultimate strength was $140 \mathrm{kN}$ on average. It was seen that Scheme "B" beams failed in flexure and had a much higher ultimate load carrying capacity than beams of Scheme "A." When initial loading was applied to beams, the matrix began to crack. When the load was increased further, JFRP began to crack, and the cracks in the JFRP began to widen, resulting in a vertical crack in the flexure zone in the beam. At a later stage, this crack began to move slowly from the bottom to the top face of the beam. The ultimate strength of Scheme "B" beams JFB4, JFB5, and JFB6 was $172 \mathrm{kN}$ on average. JFB4, JFB5, and JFB6 all failed in a same trend. The ultimate load carrying capacity of Scheme "C" beams JFB7, JFB8, and JFB9, which were strip-wrapped with JFRP, is determined experimentally. From the experimental results, it is found that the ultimate load carrying capacity for these beams was found to be greater than that for the unstrengthened beams (Scheme A) and less than that for fully wrapped beams (Scheme B). It is observed that, in Scheme C beams, the cracks were appeared first in the unwrapped portion of the beam and then in the JFRP wrapped portion, which shows that the bonding of JFRP added extra strength to the beams, which increases the ultimate load carrying capacity. When load was applied to JFB7, JFB8, and JFB9, majority of vertical cracks were observed in the mid portion of the span, which is the pure flexure zone. The JFRP did not develop even a single flexural crack, nor did it rupture. These cracks were initiated on the lower surface and propagated to the upper surface of the beam. The ultimate load carrying capacity of the JFRP strip wrapping technique has increased up to a 


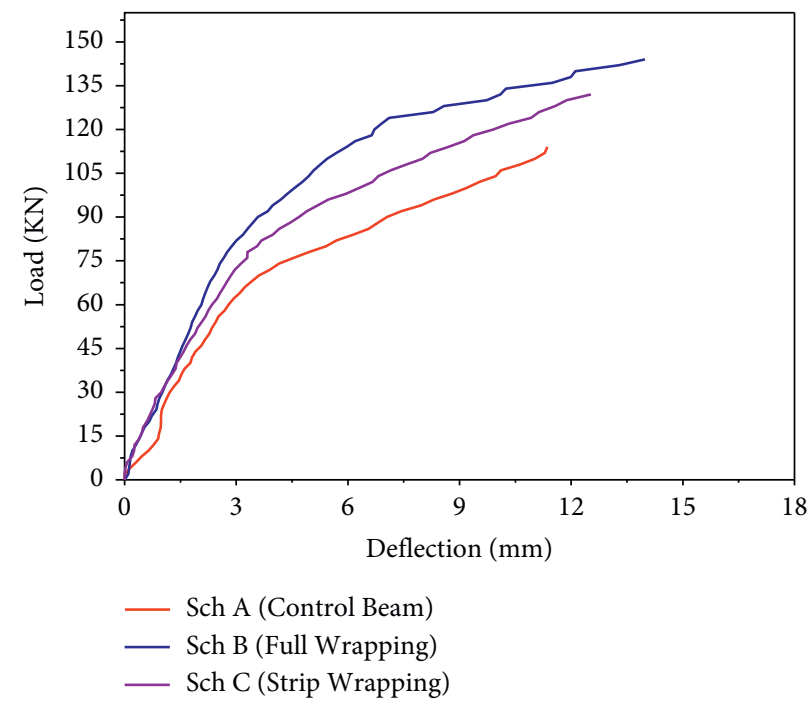

FIgURE 7: Load-deflection (average mid span) for all schemes.

Table 3: Deformability indices for beams designed to fail under flexure.

\begin{tabular}{lcccc}
\hline Designation & First crack load (kN) & $\begin{array}{c}\text { Avg. mid span deflection at first crack } \\
(\mathrm{mm})\end{array}$ & $\begin{array}{c}\text { Avg. mid span deflection at failure } \\
(\mathrm{mm})\end{array}$ & $\begin{array}{c}\text { Deformability } \\
\text { index }\end{array}$ \\
\hline Scheme A & CB1, CB2, and CB3 & 3.687 & 6.522 & 1.77 \\
Scheme B & JFB4, JFB5, and & TFB6 & The first crack deflection was not observed in fully U-wrapped beams & - \\
Scheme C & JFB7, JFB8, and & 4.531 & 10.727 & 2.36 \\
\hline
\end{tabular}

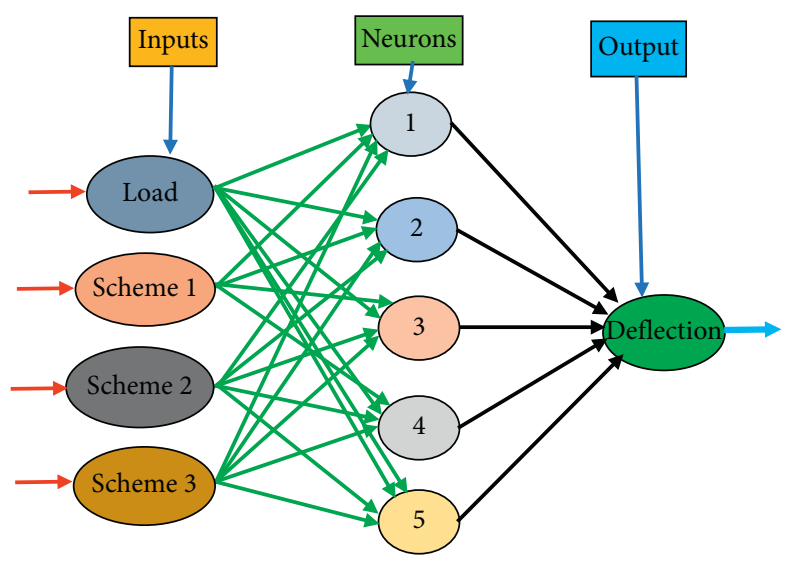

FIgURE 8: General ANN structure.

certain point, which is in between the increase in the load carrying capacities of full wrapped and control beams. The ultimate strength of $154 \mathrm{kN}$ on average was observed in Scheme "C" beams. The graphs in Figure 5 show a comparison of the ultimate failure load of different beam schemes. The use of JFRP, whether in continuous form or in strips, has the effect of delaying the formation of cracks. The study revealed that the initial cracks were caused by load. The graphs in Figure 6 show a comparison of the first crack load of different beam schemes. When the loaddeflection behaviour of retrofitted beams with continuous U-wrap JFRP was compared to strip wrapping, it was confirmed that the continuous U-wrap JFRP-retrofitted beams had a better load-deflection behaviour. Here, brittle failure of the beams was drastically managed by continuous JFRP because the beams carried large deflections before failure and thus provided adequate warnings before collapsing. The presence of strips slowed the formation of the first cracks where JFRP was bonded to the beams.

4.2. Load-Deflection Relationship Study. All of the beams' load-deflection behaviour was observed and compared among them with the same reinforcement. In addition, mid span deflections of each beam were compared to those of control beams. For Scheme A, B, and C beams, a 
TABle 4: Determination coefficient $R^{2}$ for different learning algorithms to predict deflection for Scheme A.

\begin{tabular}{lcccc}
\hline \multirow{2}{*}{ Number of hidden layers } & \multirow{2}{*}{ Neurons in hidden layer } & \multicolumn{2}{c}{ Coefficient of determination $R^{2}$} \\
& & Training data & Validating data & Testing data \\
\hline 1 & 8 & 0.99987 & 0.99978 & 0.99964 \\
1 & 10 & 0.99989 & 0.99981 & 0.99976 \\
1 & 20 & 0.99992 & 0.99983 & 0.99968 \\
1 & 25 & 0.99995 & 0.99985 & 0.99972 \\
1 & $\mathbf{3 0}$ & $\mathbf{0 . 9 9 9 9 9}$ & $\mathbf{0 . 9 9 9 8 9}$ & 0.99974 \\
1 & 40 & 0.99997 & 0.99984 & 0.99982 \\
\hline
\end{tabular}

The bold values indicate the optimum value.

TABLE 5: Determination coefficient $R^{2}$ for different learning algorithms to predict deflection for Scheme $\mathrm{B}$.

\begin{tabular}{|c|c|c|c|c|c|}
\hline \multirow{2}{*}{ Number of hidden layers } & \multirow{2}{*}{ Neurons in hidden layer } & \multicolumn{4}{|c|}{ Coefficient of determination $R^{2}$} \\
\hline & & Training data & Validating data & Testing data & All data \\
\hline 1 & 10 & 0.99974 & 0.99976 & 0.99250 & 0.99801 \\
\hline 1 & 20 & 0.99979 & 0.99979 & 0.99254 & 0.99805 \\
\hline 1 & 25 & 0.99984 & 0.99986 & 0.99260 & 0.99810 \\
\hline 1 & 30 & 0.99988 & 0.99990 & 0.99265 & 0.99815 \\
\hline 1 & 35 & 0.99992 & 0.99996 & 0.99271 & 0.99821 \\
\hline 1 & 40 & 0.99990 & 0.99992 & 0.99267 & 0.99812 \\
\hline
\end{tabular}

The bold values indicate the optimum value.

TAвLe 6: Determination coefficient $R^{2}$ for different learning algorithms to predict deflection for Scheme C.

\begin{tabular}{|c|c|c|c|c|c|}
\hline \multirow{2}{*}{ Number of hidden layers } & \multirow{2}{*}{ Neurons in hidden layer } & \multicolumn{4}{|c|}{ Coefficient of determination $R^{2}$} \\
\hline & & Training data & Validating data & Testing data & All data \\
\hline 1 & 8 & 0.99957 & 0.99778 & 0.99954 & 0.99913 \\
\hline 1 & 10 & 0.99966 & 0.99780 & 0.99958 & 0.99918 \\
\hline 1 & 20 & 0.99970 & 0.99784 & 0.99960 & 0.99925 \\
\hline 1 & 30 & 0.99973 & 0.99787 & 0.99962 & 0.99930 \\
\hline 1 & 40 & 0.99977 & 0.99789 & 0.99964 & 0.99933 \\
\hline 1 & 50 & 0.99972 & 0.99786 & 0.99961 & 0.99931 \\
\hline
\end{tabular}

The bold values indicate the optimum value.

comparative study of average load and mid span deflection behaviour is depicted in Figure 7. When Scheme B beams is bonded with fully wrapped JFRP, the behaviour was found to be superior compared to that of control beams of Scheme A. The ultimate load at failure was found to be much higher when the mid span deflection was externally bonded with JFRP. The FRP bonded to the beam, resulted in a delay in the formation of cracks. Continuous/fully wrapped FRP-retrofitted beams outperformed strip wrapping retrofitted beams in terms of load-deflection. The brittle failure can be avoided in the beams by using this configuration, which was found to be more effective, since beams have deflected and given enough warnings prior to failure.

4.3. Effect on Ductility. The ability of a reinforced structure to withstand inelastic deformation without losing its load carrying capacity prior to failure is a desirable structural property. Deformation can take the form of deflection, strain, or curvature [26]. The results demonstrated in Table 3 indicate that the wrapped JFRP beams have greater ductility than the control beam.

\section{Artificial Neural Network (ANN) Modeling}

It is recommended that a three-layer feed-forward ANN method be used, with 1 input, 1 hidden, and 1 yield layers. Figure 8 depicts the general ANN structure of the defined problem. For the deflection, the input layer had 4 neurons, whereas the yield layer only had 1 . The findings were sent into the ANN model, with each piece of data representing a complex aggregation of process variables. The training, validation, and testing data were separated into three groups, with 60,20 , and $20 \%$ of all training, validation, and testing data, respectively. The model was trained using the Levenberg-Marquardt approach. Learning networks have made use of it. The artificial neural network (ANN) was repeatedly trained to lessen the MSE score metric among the ANN outputs and the target data. The outcomes of ANN computations for the preceding network are shown in Tables 4-6 for Schemes A, B, and C, respectively. With the partial data, ANN modeling using less neurons inside a hidden layer correctly predicts the deflection in all circumstances. Despite this, because to the optimal point of the modeling coefficient, 30 neurons in a solitary hidden layer architecture were regarded to reflect 

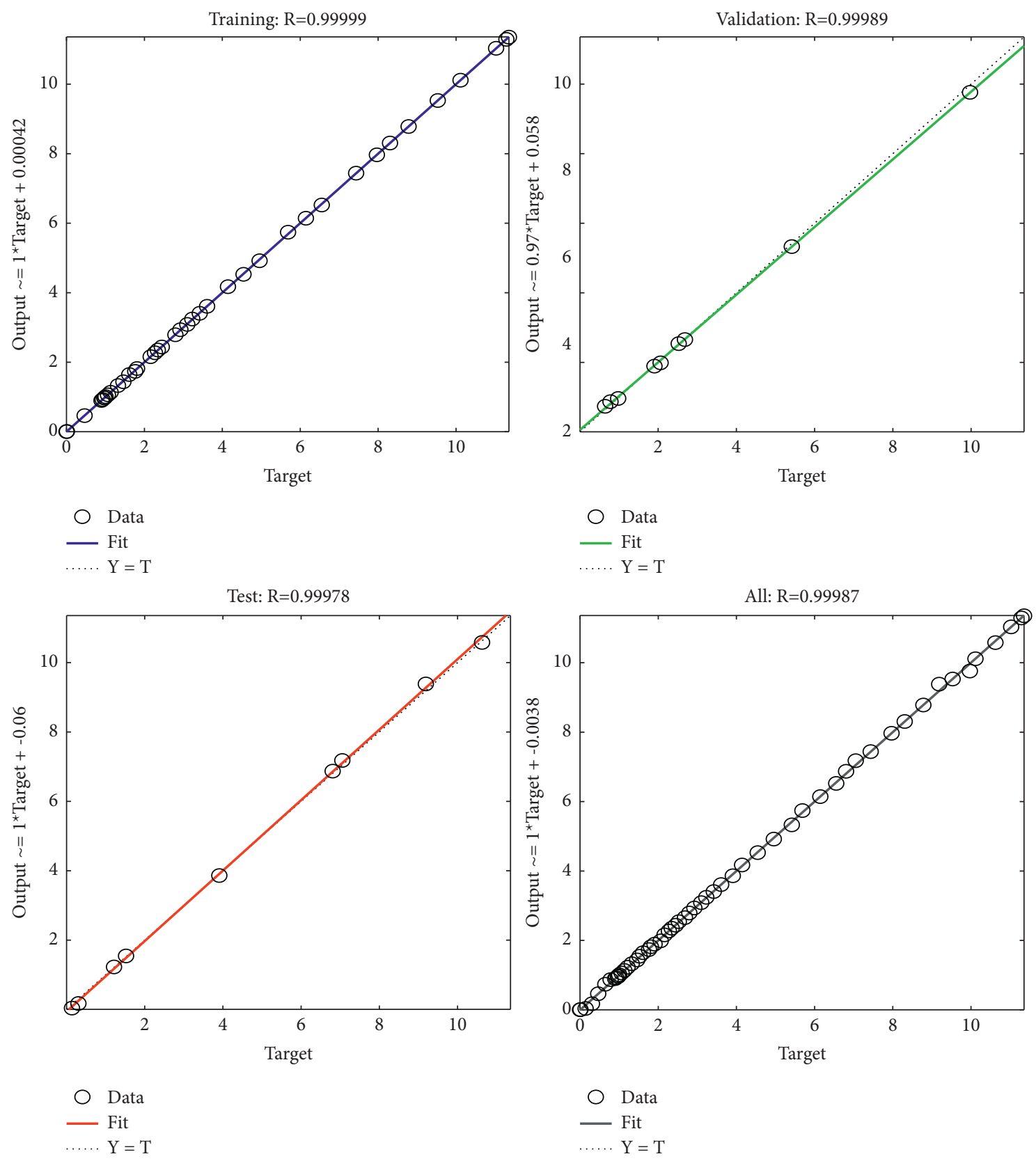

FIGURE 9: Neural network training regression analysis (optimal performance at 30 neurons in the hidden layer for Scheme A).

the ANN modeling outcome (for Scheme A). The deflection produced from ANN modeling for hidden neurons inside the hidden layer network is shown in Figure 9 (Scheme A), Figure 10 (Scheme B), and Figure 11 (Scheme C). For all retrofitting strategies, experimental data are compared to ANN's estimated deflection data. Figure 12 (Scheme A), Figure 13 (Scheme B), and Figure 14 (Scheme
C) show the correlations between actual and expected outcomes. Scheme A, B, and C samples' observed responses (deflection) are compared to the model's projected responses, and the relative correlation charts are shown. The " $R$ ") values for the above schemes are found to be in the region of 0.99 , suggesting that the test values and anticipated values are highly correlated. 

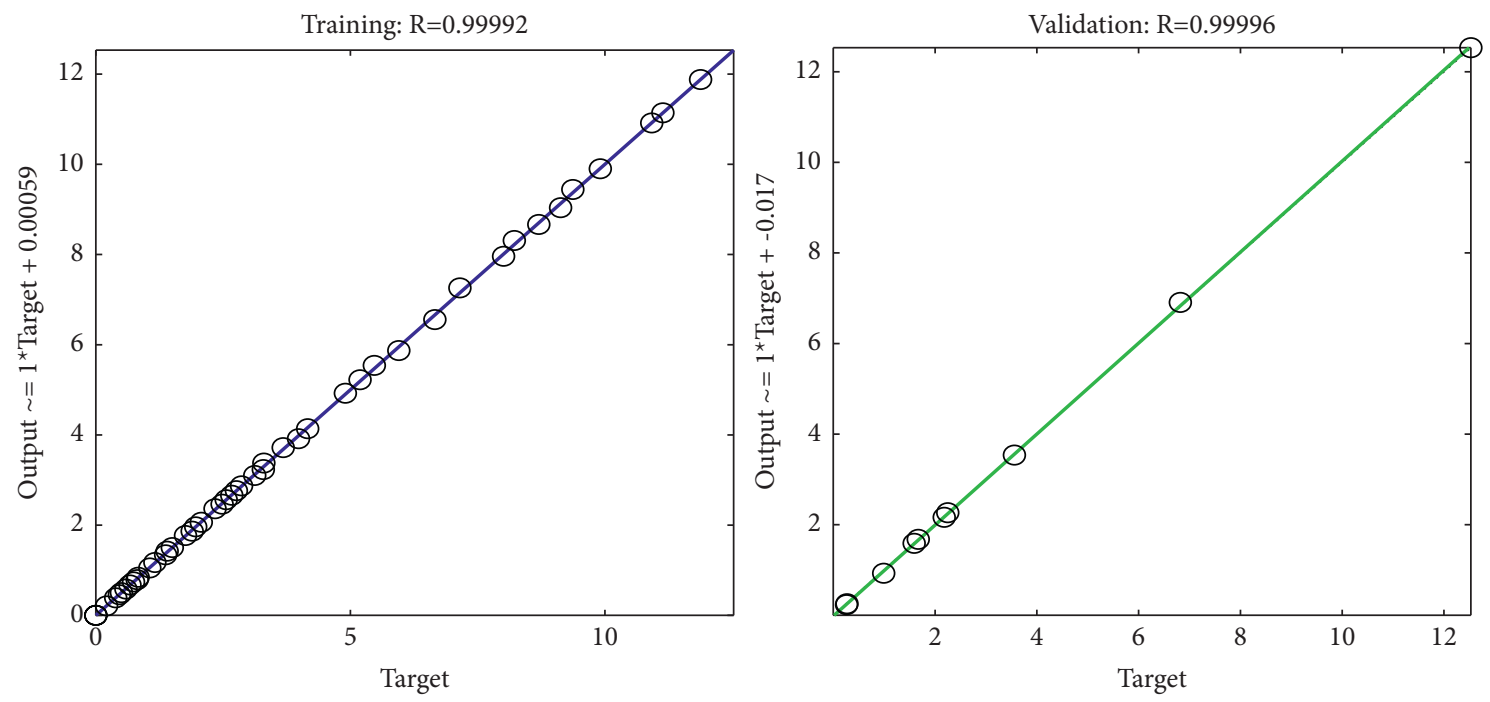

$$
\begin{aligned}
& \text { Data } \\
& \text { Fit } \\
& \ldots \ldots . \mathrm{Y}=\mathrm{T}
\end{aligned}
$$

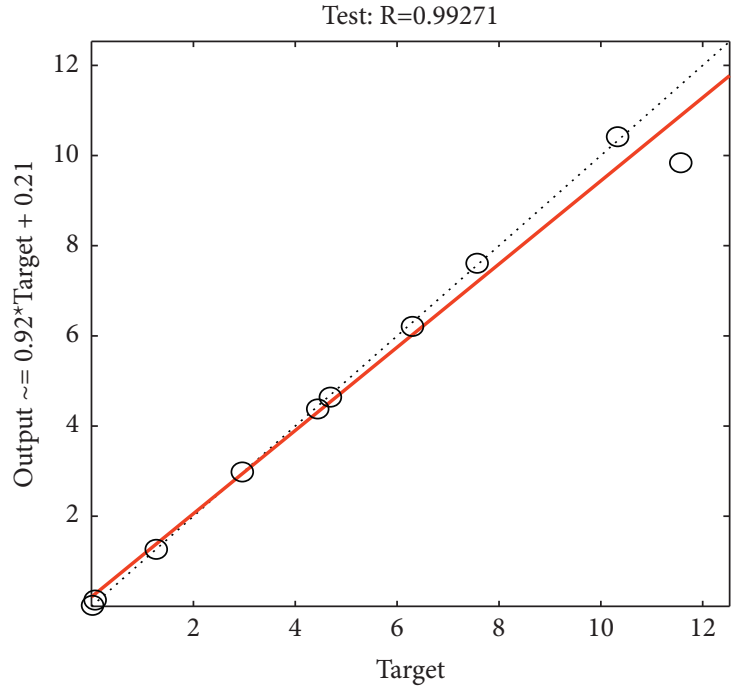

O Data

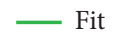

$$
\cdots \cdot \mathrm{Y}=\mathrm{T}
$$

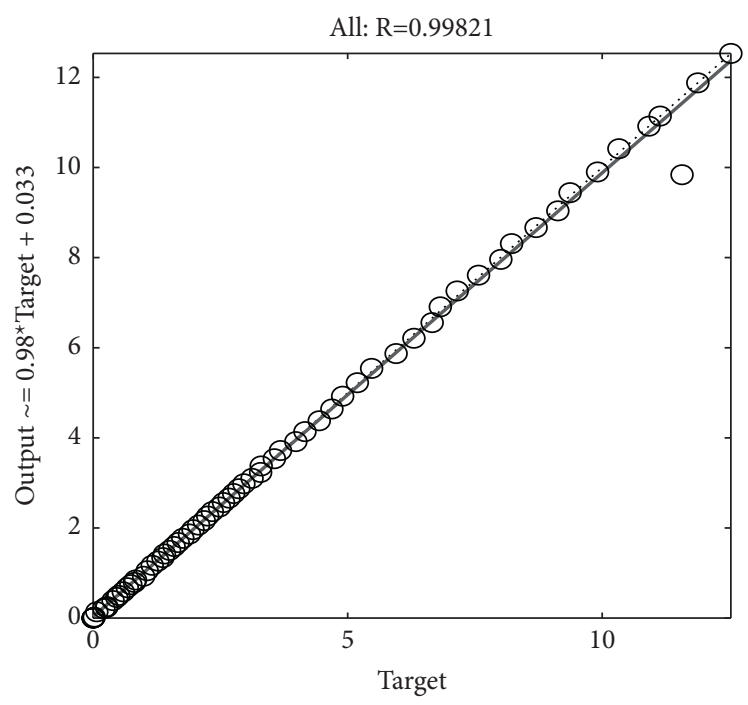

$$
\begin{aligned}
& \bigcirc \quad \text { Data } \\
& - \text { Fit } \\
& \text {.... Y Y }=\mathrm{T}
\end{aligned}
$$

$$
\begin{aligned}
& \text { Data } \\
& \text { Fit } \\
& \ldots \ldots \text { Y }=\mathrm{T}
\end{aligned}
$$

FIGURE 10: Neural network training regression analysis (optimal performance at 40 neurons in the hidden layer for Scheme B). 

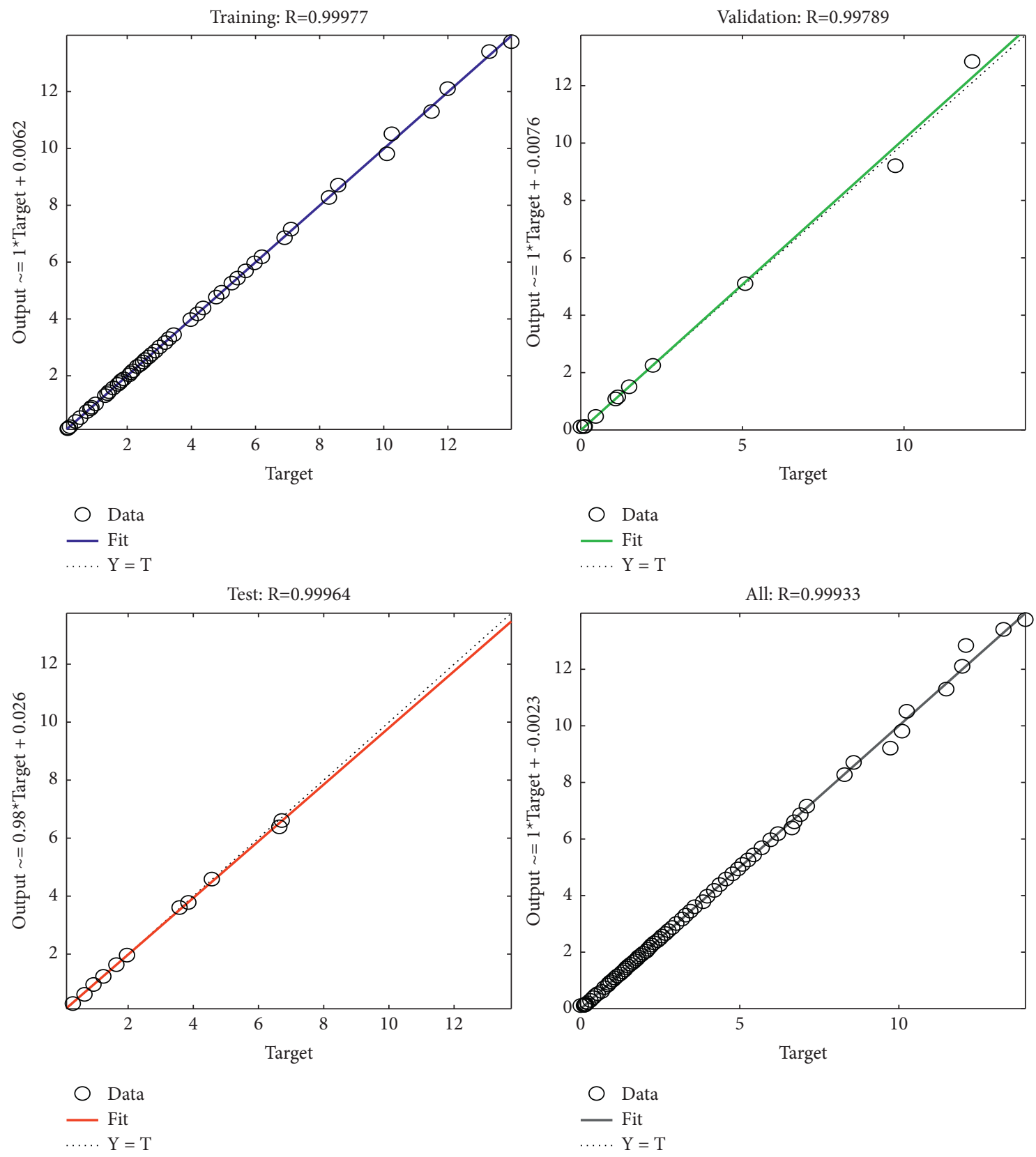

FIGURE 11: Neural network training regression analysis (optimal performance at 50 neurons in the hidden layer for Scheme C).

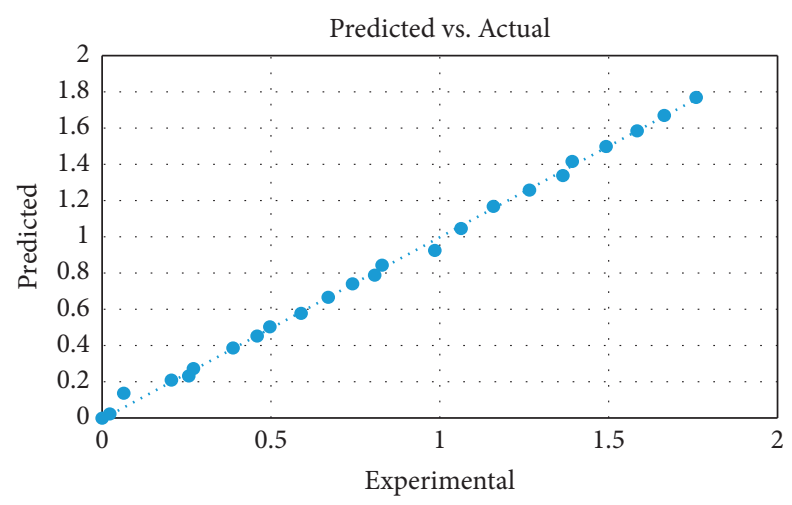

FIgure 12: Correlation graph for Scheme A specimen. 


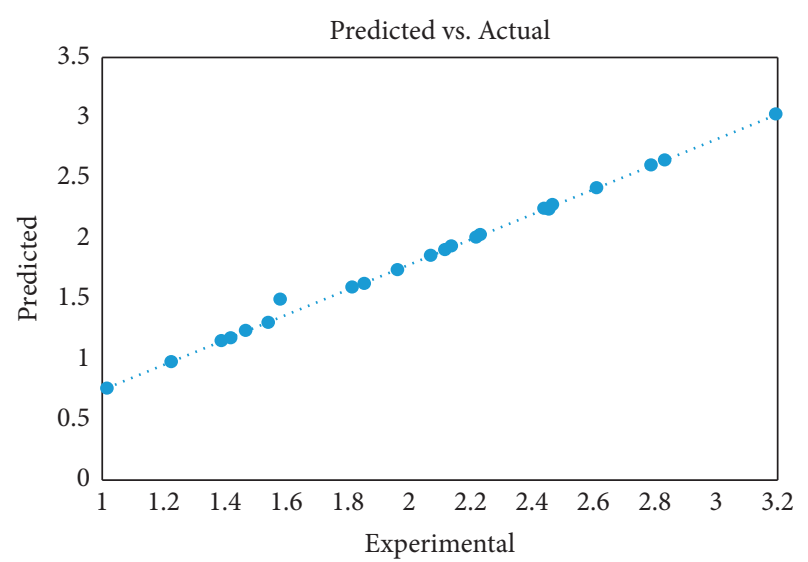

Figure 13: Correlation graph for Scheme B specimen.

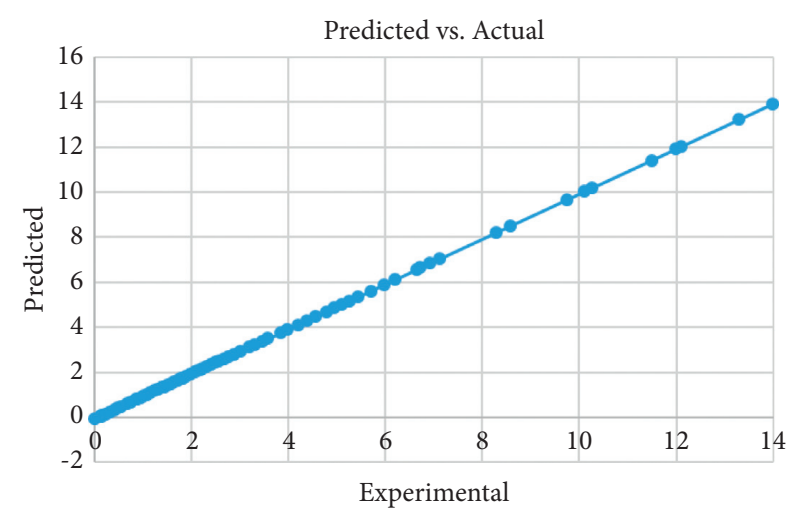

Figure 14: Correlation graph for Scheme C specimen.

\section{Conclusions}

The applicability and efficiency of JFRP as a strengthening material, as well as the effect of various wrapping techniques on the strengthening of beams, were experimentally investigated in this study.

(i) Load carrying capacity of the single layer of fully wrapped and strip-wrapped beams is improved by $23 \%$ and $10 \%$, respectively, in comparison with the control beams. The JFRP bonded to the beam, which inhibited the development of cracks and delayed their formation. When the JFRP was used in the flexure deficient beams, initial cracks formed at higher loads than their respective control beams.

(ii) It showed that the use of polymer composites was effective for the flexural strengthening of structures. In all the strengthened beams, ultimate strength was found to be increased with the increase in laminate width, and strip wrapping exhibits lower load carrying capacity than full wrapping. The load-deflection behaviour of JFRP-enhanced beams was superior to that of controlled beams. The failure pattern of a JFRP-strengthened beam showed a significant difference. In JFB4, JFB5, and JFB6, a single crack has been developed in the flexural region and two cracks were developed away from it. (iii) Widening of the cracks within the flexure zone was noticed as the load increased, but fortunately, there was no brittle failure maybe because of the good amount of confinement provided by the JFRP in the strengthened beam. The ductile behaviour obtained with JFRP provided sufficient warning prior to ultimate failure.

(iv) In Scheme C beams (JFB7, JFB8, and JFB9), favorable observation was made that flexural cracks were formed only in the beam area and not on the JFRP, as well as failure, which supports the experimental outcomes.

(v) The predicted values agree well with the experimental values, as evidenced by the good agreement of $R^{2}$ values of deflection.

(vi) The results of the study, experiments, and data analysis have confirmed that the efficiency of the beams and also the load carrying capacity can be increased by using JFRP, which has high potential for enhancing these characteristics. The study reveals the use of natural fibres such as jute in FRP for increasing the flexural strength of concrete structures is found to be a good alternative method.

\section{Data Availability}

The data used to support the findings of this study are included within the article.

\section{Conflicts of Interest}

The authors declare that there are no conflicts of interest regarding the publication of this article.

\section{Acknowledgments}

The authors acknowledge BBR India Pvt. Ltd., and Miki Steels Pvt. Ltd., Bengaluru, for assistance during this study.

\section{References}

[1] M. Badawi and K. Soudki, "Effect of FRP wraps on the tensile strength of plain and reinforced concrete beams," in Proceedings of the 4th Structural Specialty Conference, pp. 1-10, Canada, June 2002.

[2] H. Toutanji, L. Zhao, and Y. Zhang, "Flexural behavior of reinforced concrete beams externally strengthened with CFRP sheets bonded with an inorganic matrix," Engineering Structures, vol. 28, no. 4, pp. 557-566, 2006.

[3] M. R. Esfahani, M. R. Kianoush, and A. R. Tajari, "Flexural behaviour of reinforced concrete beams strengthened by CFRP sheets," Engineering Structures, vol. 29, no. 10, pp. 2428-2444, 2007.

[4] S. Syed Ibrahim, S. Eswari, and T. Sundararajan, "Experimental investigation on FRC beams strengthened with GFRP laminates," Electronic Journal of Structural Engineering, vol. 15, no. 1, pp. 55-59, 2015.

[5] K. Al-Deen Bsisu, Y. Hunaiti, and Y. Raja, "Flexural ductility behavior of strengthened reinforced concrete beams using steel and CFRP plates," Jordan Journal of Civil Engineering, vol. 6, no. 3, pp. 304-312, 2012. 
[6] A. F. Ashour, S. A. El-Refaie, and S. W. Garrity, "Flexural strengthening of RC continuous beams using CFRP laminates," Cement and Concrete Composites, vol. 26, no. 7, pp. 765-775, 2004.

[7] H. N. Garden and L. C. Hollaway, "An experimental study of the influence of plate end anchorage of carbon fibre composite plates used to strengthen reinforced concrete beams," Composite Structures, vol. 42, no. 2, pp. 175-188, 1998.

[8] S. T. Smith and J. G. Teng, "FRP-strengthened RC beams. I: review of debonding strength models," Engineering Structures, vol. 24, no. 4, pp. 385-395, 2002.

[9] M. Mahalingam, R. P. N. Rao, and S. Kannan, "Ductility behavior fibres reinforced concrete beams strengthened with externally bonded Glass fibres reinforced polymer laminates," American Journal of Applied Sciences, vol. 10, no. 1, pp. 107-111, 2013.

[10] A. Khalifa, G. Tumialan, A. Nanni, and A. Belarbi, "Shear strengthening of continuous RC Beams using externally bonded CFRP sheets," in Proceedings of the 4th International Symposium on FRP for Reinforcement of Concrete Structures, pp. 995-1008, Baltimore, MD, USA, October 1999.

[11] D. P. Archana and H. N. Jagannatha Reddy, "Potential of natural fibres for strengthening existing structures-a review," International Journal of Structural Engineering and Analysis, vol. 4, no. 2, pp. 38-46, 2018.

[12] T. Sen and H. N. Jagannatha Reddy, "Strengthening of RC beams in Flexure using natural jute fibre textile reinforced composite system and its comparative study with CFRP and GFRP strengthening systems," International Journal of Sustainable Built Environment, vol. 2, no. 1, pp. 41-55, 2013.

[13] A. Alam, K. Alriyami, M. Z. Jumaat, and Z. C. Muda, "Development of high strength natural fibre based composite plates for potential application in retrofitting of RC structure," Indian Journal of Science and Technology, vol. 8, no. 15, 2015.

[14] M. A. R. Bhutta, A. K. Nur Hafizah, M. Y. Jamaludin, M. H. Warid, M. Ismail, and M. Azman, "Strengthening reinforced concrete beams using kenaf fiber reinforced polymer composite laminates," in Proceedings of the $3 \mathrm{rd}$ International Conference on Sustainable Construction Materials and Technologies, Kyoto, Japan, August 2013.

[15] S. C. Chin, F. S. Tong, D. S. Ing, J. Gimbun, H. R. Ong, and J. P. Serigar, Strengthening performance of PALF-epoxy composite plate on reinforced concrete beams," IOP Conference Series: Materials Science and Engineering, vol. 318, Article ID 012026, 2018.

[16] G. Di Luccio, L. Michel, E. Ferrier, and E. Martinelli, "Seismic retrofitting of RC walls externally strengthened by flax-FRP strips," Composites Part B: Engineering, vol. 127, pp. 133-149, 2017.

[17] T. Sen and H. N. J. Reddy, "Flexural Strengthening of RC beams using natural sisal and artificial carbon and glass fabric reinforced composite system," Sustainable Cities and Society, vol. 10, pp. 195-206, 2014.

[18] M. A. Alam and K. Al Riyami, "Shear strengthening of reinforced concrete beam using natural fibre reinforced polymer laminates," Construction and Building Materials, vol. 162, pp. 683-696, 2018.

[19] T. Sen and H. N. J. Reddy, "A Numerical study of Strengthening of RCC beam using natural Bamboo fibre," International Journal of Computer Theory and Engineering, vol. 3, no. 5, 2011.

[20] L. Ghalieh, E. Awwad, G. Saad, H. Khatib, and M. Mabsout, "Concrete columns wrapped with hemp fiber reinforced polymer - an experimental study," Procedia Engineering, vol. 200, pp. 440-447, 2017.

[21] T. Sen and H. N. J. Reddy, "Finite element simulation of Retrofitting of RCC beam using coir fibre composite," International Journal of Innovation, Management and Technology, vol. 2, no. 2, 2011.

[22] T. K. Mulenga, A. U. Ude, and C. Vivekanandhan, "Techniques for modelling and optimizing the mechanical properties of natural fiber composites: a review," Fibers, vol. 9, no. $1,2021$.

[23] T. Naresh Kumar, B. Murali, and J. Arulmani, "Machining characteristics of natural fiber particle reinforced polymer composite material using artificial neural network," International Journal of Innovative Technology and Exploring Engineering, vol. 8, no. 9, pp. 3350-3354, 2019.

[24] S. Pujari, A. Ramakrishna, and K. T. Balaram Padal, "Comparison of ANN and regression analysis for predicting the water absorption behaviour of jute and banana fiber reinforced epoxy composites," Materials Today proceedings, vol. 4, no. 2, pp. 1626-1633, 2017.

[25] D. P. Archana, H. N. Jagannatha Reddy, R. Prabhakara, M. U. Aswath, and A. Chandrashekar, "Processing and properties of biodegradable composites to strengthen structures," The Institution of Engineers: Series C, 2021.

[26] E. Natarajan, "Ductility response of hybrid fibre reinforced concrete beams," Journal of Urban and Environmental Engineering, vol. 11, no. 2, pp. 174-179, 2017. 